\title{
Chronic intractable diarrhea caused by gastrointestinal mastocytosis
}

\author{
Hyungil Seo ${ }^{1}$, Sang Hyoung Park ${ }^{2}$, Jeong-Sik Byeon ${ }^{2}$, Chang Gok Woo ${ }^{3}$, Seung-Mo Hong ${ }^{3}$, Kiju Chang ${ }^{1}$, \\ Hoonsub So ${ }^{2}$, Minseob Kwak ${ }^{2}$, Wan Soo Kim², Jeong-Mi Lee ${ }^{2}$, Dong-Hoon Yang ${ }^{2}$, Kyung-Jo Kim², \\ Byong Duk Ye ${ }^{2}$, Seung-Jae Myung ${ }^{2}$, Suk-Kyun Yang ${ }^{2}$ \\ Departments of Internal Medicine, ${ }^{2}$ Gastroenterology, and ${ }^{3}$ Pathology, Asan Medical Center, University of Ulsan College of Medicine, Seoul, Korea
}

As mast cells have been highlighted in the pathogenesis of diarrhea-predominant irritable bowel syndrome, a new term "mastocytic enterocolitis" was suggested by Jakate and colleagues to describe an increase in mucosal mast cells in patients with chronic intractable diarrhea and favorable response to treatment with antihistamines. Although it is not an established disease entity, two cases have been reported in the English medical literature. Here, for the first time in Asia, we report another case of chronic intractable diarrhea caused by gastrointestinal mastocytosis. The patient was a 70-year-old male with chronic intractable diarrhea for 3 months; the cause of the diarrhea remained obscure even after exhaustive evaluation. However, biopsy specimens from the jejunum were found to have increased mast cell infiltration, and the patient was successfully treated with antihistamines. (Intest Res 2016;14:280-284)

Key Words: Mastocytic enterocolitis; Mast cells; Diarrhea

\section{INTRODUCTION}

Chronic diarrhea has numerous etiologies, and the most common causes are IBS, IBD, malabsorption syndrome, chronic infections, and idiopathic secretory diarrhea. ${ }^{1}$ However, in some patients with chronic diarrhea, the diagnosis remains unclear even after a thorough evaluation including a detailed history, physical examination, routine laboratory tests, stool examination, radiography, endoscopy, and biopsy. Jakate and colleagues found that a subset of patients with chronic intractable diarrhea had increased mast cell infiltration into the gut mucosa. The researchers termed that distinctive morphologic disorder mastocytic enterocolitis. ${ }^{2}$ We recently encountered a patient with chronic diarrhea

Received March 24, 2015. Revised June 5, 2015. Accepted June 22, 2015 Correspondence to Sang Hyoung Park, Department of Gastroenterology, University of Ulsan College of Medicine, Asan Medical Center, 88 Olympic-ro 43-gil, Songpa-gu, Seoul 05505, Korea. Tel: +82-2-3010-5768, Fax: +82-2476-0824,E-mail:umdalpin@hanmail.net

Financial support: None. Conflict of interest: None. who was diagnosed histologically with gastrointestinal mastocytosis and was successfully treated with antihistamines. We present this case with a review of the relevant literature.

\section{CASE REPORT}

A 70-year-old man visited our hospital complaining of chronic diarrhea for 3 months. He had increased bowel movements with excessive bowel sounds approximately half an hour after a meal, his stools were almost watery, and the frequency of his bowel movements was approximately 2-4 times per day. The diarrhea was not accompanied by abdominal pain before or after a bowel movement. The patient had lost $30 \mathrm{~kg}$ of weight (from $100 \mathrm{~kg}$ to $70 \mathrm{~kg}$ ) in the 3 months since the diarrhea had begun. Before visiting our hospital, he had been admitted to two other hospitals, where he underwent esophagogastroduodenoscopy, colonoscopy, and an abdominopelvic CT scan, but none of the studies revealed the cause of his chronic diarrhea.

He was taking antihypertensives (amlodipine $5 \mathrm{mg} /$ day,

- Copyright 2016. Korean Association for the Study of Intestinal Diseases. All rights reserved.

This is an Open Access article distributed under the terms of the Creative Commons Attribution Non-Commercial License (http://creativecommons.org/licenses/by-nc/4.0)

which permits unrestricted non-commercial use, distribution, and reproduction in any medium, provided the original work is properly cited. 
olmesartan $20 \mathrm{mg}$ /day, and atenolol $50 \mathrm{mg} /$ day) and an oral hypoglycemic drug (glimepiride $2 \mathrm{mg} /$ day.) Twelve years previously, he had suffered from jaundice with intrahepatic stones and undergone removal of the stones via percutaneous transhepatic cholangioscopy three times. He had also undergone open cholecystectomy for empyema of the gallbladder 8 years previously. He had a 40-pack-year history of smoking but had stopped smoking 12 years previously.

He looked ill. His body height was $172 \mathrm{~cm}$, and his weight was $71 \mathrm{~kg}$ (BMI $24 \mathrm{~kg} / \mathrm{m}^{2}$ ). At the time of admission, his blood pressure, pulse rate, respiratory rate, and body temperature were 151/110 mmHg, 109 beats/min, 16 breaths/ min, and $36.5^{\circ} \mathrm{C}$, respectively. A peripheral blood test showed leukocyte, hemoglobin, and platelet levels of 8,500/ $\mathrm{mm}^{3}$ (granulocytes, 63\%; lymphocytes, 25\%; and monocytes, $11 \%$ ), $17.9 \mathrm{~g} / \mathrm{dL}$, and $123,000 / \mathrm{mm}^{3}$, respectively. A blood chemistry test revealed that levels of BUN/Cr, albumin, AST/ ALT, ALP, amylase/lipase, and CRP were 12/0.99 mg/dL, 2.9 $\mathrm{g} / \mathrm{dL}, 14 / 10 \mathrm{IU} / \mathrm{L}, 77 \mathrm{IU} / \mathrm{L}, 58 / 27 \mathrm{U} / \mathrm{L}$, and $0.25 \mathrm{mg} / \mathrm{dL}$, respectively. Electrolyte levels were within the normal ranges (sodium $135 \mathrm{mEq} / \mathrm{L}$ and potassium $4.1 \mathrm{mEq} / \mathrm{L}$ ). Glycated hemoglobin level was 5.5\%. A qualitative test of urine 5-hydroxyindoleacetic acid showed a negative result. The patient was in a euthyroid state (thyroid-stimulating hormone 3.6 $\mu \mathrm{U} / \mathrm{mL}$ and free T4 $1.1 \mathrm{ng} / \mathrm{dL}$ ). The fecal occult blood test (immune latex agglutination method) result was negative. A routine stool examination showed no helminth ova, protozoa cysts, or trophozoites, and a stool Gram stain showed no leukocytes. There was no growth of Shigella, Salmonella, or Yersinia species on the stool culture. A Clostridium difficile toxin assay and culture showed a negative result.

Esophagogastroduodenoscopy did not detect any abnormal findings in the esophagus; however, multiple erosions and whitish scar changes were observed in the gastric body and antrum. Mucosal nodularity was observed in the second portion of the duodenum. Colonoscopy did not detect any abnormalities except one small polyp in the cecum and one in the rectum. Biopsy specimens were randomly obtained at each segment of the entire colon and the terminal ileum. A small bowel series showed no abnormal findings.

Histological examination of the stomach revealed a moderate mixed lymphoplasmacytic infiltration in the lamina propria. Duodenal biopsy showed chronic severe duodenitis with mucin depletion and flattening of the villi. Mild lymphocytic infiltrations were observed in the ileal and colonic biopsies of each segment of the entire colon.

The patient was treated empirically with antiparasitic drugs (400 mg of albendazole once and $1.8 \mathrm{~g}$ of praziqu- antel 3 times per day for 2 days) and antidiarrheal drugs (loperamide, which was initially started with a dose of $3 \mathrm{mg} /$ day and later escalated to $9 \mathrm{mg} /$ day; $1 \mathrm{~g}$ of a compound of bismuth, tannalbin, and kaolin 3 times per day; and $10 \mathrm{mg}$ of codeine 3 times per day); however, the diarrhea continued. The patient received octreotide $(0.05 \mathrm{mg}$ subcutaneously 3 times per day), which was unable to relieve his symptom.

Because the cause of the diarrhea was still unclear after thorough evaluation, a second esophagogastroduodenoscopy was conducted. This time the endoscopy was advanced farther beyond the second portion of the duodenum, with the purpose of examining the proximal small bowel as far as possible. Mucosal changes indicative of metaplasia were detected from the second portion of the duodenum to the proximal jejunum. However, the most distal small bowel that could be observed during the endoscopy appeared normal. Biopsy specimens were randomly obtained from the duodenal bulb to the proximal jejunum (Fig. 1). Duodenal biopsy revealed blunting of the intestinal villi, detachment of surface epithelial cells, depletion of goblet cells, and moderate lymphoplasmacytic and mild eosinophilic infiltration in the lamina propria and crypts. Increased mast cell infiltrations into the lamina propria with more than 50 mast cells per high power field were observed by toluidine blue staining and CD117 (KIT) immunohistochemical staining (Fig. 2). Jejunal biopsies demonstrated similar histological features.

Treatment with hydroxyzine ( $10 \mathrm{mg}$ per day), famotidine (20 mg per day), and ranitidine (300 mg per day) was started

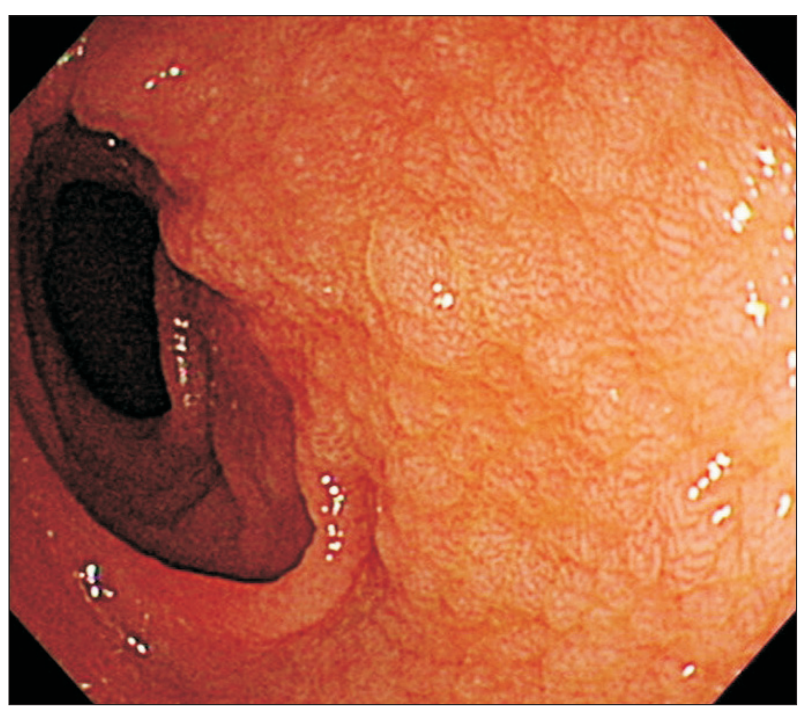

Fig. 1. Endoscopic findings of the jejunum in the study patient. Mucosal changes indicative of metaplasia and mucosal nodularity were observed. 


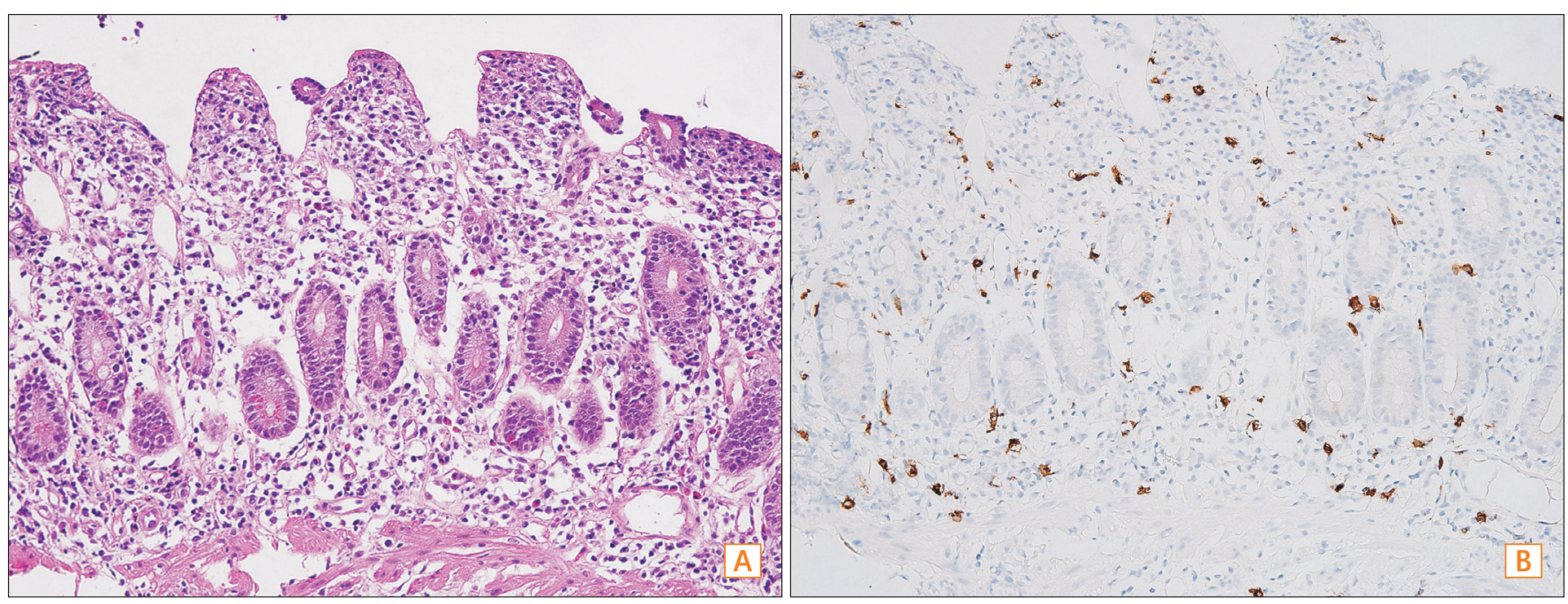

Fig. 2. Representative histological and CD117 (KIT) immunohistochemical images of the study patient. (A) Duodenal biopsy revealed blunting of the intestinal villi, detachment of surface epithelial cells, depletion of goblet cells, and moderate lymphoplasmacytic and mild eosinophilic infiltration into the lamina propria and crypts $(\mathrm{HEE}, \times 400)$. (B) Increased mast cell infiltrations into the lamina propria; $>50$ mast cell infiltrations per high power field were observed (toluidine blue staining and CD117 [KIT] immunohistochemical staining, $\times 400$ ).

soon after confirmation of gastrointestinal mastocytosis. The patient returned to the outpatient clinic 2 weeks later, and his symptoms of chronic diarrhea were substantially improved. He took both $\mathrm{H} 1$ and $\mathrm{H} 2$ antagonists for a further 2 weeks, and his treatment was discontinued thereafter. There was no relapse of diarrhea up to his last visit to our hospital, which was 11 months after discontinuation of the medication.

\section{DISCUSSION}

Mast cells play an important role in immunoregulationparticularly at the mucosal border between the body and the environment. ${ }^{3}$ Mast cells are preferentially located adjacent to nerve fibers in the gastrointestinal lamina propria. ${ }^{3,4}$ Mast cells can be activated not only by the traditionally well-known IgE-mediated type I hypersensitivity reaction but also by stress, nerve damage, infection, and a variety of inflammatory events. ${ }^{5}$ Reactions secondary to degranulation of various inflammatory mediators from activated mast cells can alter intestinal motility, visceral sensitivity, and mucosal and epithelial gut barrier function and can result in hypersecretion and power propulsion, causing diarrhea and abdominal pain. ${ }^{4,6}$ Accordingly, mast cells have attracted increasing attention as factors that play an important role in the pathogenesis of diarrhea-predominant IBS. Excess mast cells can be evaluated via immunohistochemical analysis for CD117, mast cell tryptase, or Giemsa stain. ${ }^{3}$ Several studies have shown that increased numbers of mast cells are pres- ent in the jejunum, terminal ileum, cecum, and colon of patients with IBS. ${ }^{7}$

Jakate and colleagues assessed the concentration of mast cells in randomly obtained colonic or duodenal biopsy specimens from 47 patients with chronic intractable diarrhea by using immunohistochemical staining for mast cell tryptase. ${ }^{2}$ The biopsy specimens in that study from patients with chronic intractable diarrhea were found to have a higher concentration of mast cells (mean \pm SD, $25.7 \pm 4.5$ cells per high power field) compared with biopsy specimens from 50 control patients without diarrhea (13.3 \pm 2.5$)$ and 63 patients with other specific diseases causing diarrhea (12.3 \pm 2.3$)$. Seventy percent $(33 / 47)$ of patients with chronic intractable diarrhea in that cohort had more than 20 mast cells per high power field in their intestinal mucosae, which represented 2 standard deviations beyond the control. Interestingly, there was cessation or significant reduction of diarrhea in $22(67 \%)$ of 33 study patients in the Jakate study when those patients received $\mathrm{H} 1$ and $\mathrm{H} 2$ receptor antagonists with or without a mast cell mediator release inhibitor. To describe the subset of patients with those distinctive histopathologic findings and favorable response to treatment with histamine antagonists, Jakate and coworkers suggested the new term mastocytic enterocolitis.

Two case reports followed the study by Jakate and coworkers. One involved a 32-year-old woman with grossly bloody, loose stools; abdominal pain; and a borderline increased number of mast cells ( 20 cells per high power field) in the colon. ${ }^{8}$ Her symptoms were improved after 5 months of 
treatment with oral cromolyn, a mast cell stabilizer. The other involved a 49-year-old male with rheumatoid arthritis who was taking methotrexate, developed chronic diarrhea and abdominal pain, and was found to have high amounts of mucosal mast cells (up to 30 cells per high power field) in the gastric antrum and duodenum. ${ }^{9}$ The patient was treated with $\mathrm{H} 1$ and $\mathrm{H} 2$ receptor antagonists. His symptoms were improved 2 weeks after beginning the treatment, and he had no symptoms of chronic diarrhea after 26 weeks.

Taking together the study by Jakate and colleagues, the two case reports, and our current case, we contend that it may take a few weeks for patients with mastocytic enterocolitis to show improvements in their symptoms after taking antihistamines. However, the appropriate treatment duration of antihistamines is not clear. Only one case showed a longterm effect of antihistamines in mastocytic enterocolitis, but biopsy specimens showed persistent mast cell infiltration even after symptoms had completely resolved. ${ }^{9}$

Mast cell stabilizers inhibit the degranulation of inflammatory mediators, and antihistamines block the effect of histamines secreted from mast cells. Because those medications do not directly decrease mast cell infiltration but only suppress mast cell activity and the effects of its mediators, the persistence of mast cell infiltration after receiving those medications does not seem odd. Compared with the previous case report, our current case showed a considerable follow-up period free of recurrent diarrhea-especially after discontinuation of the medication. The prolonged remission period might be a clinical feature suggestive of histopathologic resolution, but we cannot determine whether a histological change occurred, because a follow-up endoscopy and biopsy were not conducted in our patient. Further studies are required to establish the natural course of illness for mastocytic enterocolitis, including histopathologic changes. More information on the epidemiological and clinical features will help identify possible causes for mast cell infiltration in a subset of patients with chronic intractable diarrhea and introduce the potential of treatment to reverse the histopathologic changes rather than merely control the symptoms.

Although we failed to rule out a diagnosis of systemic mastocytosis in our current case, this diagnosis should be excluded in patients with increased mast cell infiltrates in the gastrointestinal tract. Additionally, the presence of mast cell aggregates in the bone marrow or extracutaneous organs is the major diagnostic criterion for systemic mastocytosis. Minor diagnostic criteria for systemic mastocytosis include coexpression of CD25 by neoplastic mast cells, $25 \%$ of mast cells having spindle-shaped or atypical morphology, the presence of an activating point mutation in codon 816 of $K I T$, and serum total tryptase $>20 \mathrm{ng} / \mathrm{mL}$. A diagnosis of systemic mastocytosis is made on the basis of 1 major and 1 minor or $\geq 3$ minor criteria. ${ }^{10}$ In a study by Doyle and colleagues of the clinicopathologic features of 24 patients with systemic mastocytosis involving the gastrointestinal tract, 7 patients (30\%) had no skin involvement at the age of diagnosis. ${ }^{11}$ Three patients in that study had diarrhea and were diagnosed with systemic mastocytosis initially based on gastrointestinal biopsies; bone marrow biopsies later revealed bone marrow involvement. In the two previous case reports of mastocytic enterocolitis, the patients underwent thorough evaluation, including bone marrow biopsies, to exclude systemic mastocytosis. ${ }^{8,9}$

Doyle and coworkers not only previously studied patients who had systemic mastocytosis with gastrointestinal tract involvement but also evaluated mucosal mast cell density in patients with IBS and asymptomatic patients (100 patients in each group). ${ }^{11}$ The concentration of mast cells for asymptomatic patients and patients with IBS was highly variable (11-55 cells per high power field versus 13-59 cells per high power field, respectively). Although patients with diarrhea-predominant IBS have mildly increased numbers of mast cells, the overlap is too great for the difference to be clinically useful. These findings argue against the concept of mastocytic enterocolitis. The authors suggested the possibility that some patients in the study by Jakate et al. may have had inappropriately increased mast cell activity, not an abnormal proliferation of mast cells. Interestingly, the mast cell densities in the patients with diarrhea-predominant IBS in both studies are comparable, but asymptomatic patients from the study by Doyle et al. had much higher mast cell concentration than did the cases in the study by Jakate et al. Further studies that comprise larger numbers of asymptomatic patients will help determine variation in mast cell count in normal adults.

Again, mastocytic enterocolitis is not yet a clearly established disease entity. However, because of the potential benefit from treatment with antihistamines, such a diagnosis should be considered in patients with unexplained chronic diarrhea. Regardless of whether the mastocytic enterocolitis is a true entity separate from diarrhea-predominant IBS or not, it seems reasonable that all patients with chronic diarrhea whose endoscopic findings and histopathologic findings via standard $\mathrm{H} \& \mathrm{E}$ are normal should undergo evaluation of gastrointestinal mucosal mast cells. 


\section{REFERENCES}

1. Fine KD, Schiller LR. AGA technical review on the evaluation and management of chronic diarrhea. Gastroenterology 1999;116:1464-1486.

2. Jakate S, Demeo M, John R, Tobin M, Keshavarzian A. Mastocytic enterocolitis: increased mucosal mast cells in chronic intractable diarrhea. Arch Pathol Lab Med 2006;130:362-367.

3. Ramsay DB, Stephen S, Borum M, Voltaggio L, Doman DB. Mast cells in gastrointestinal disease. Gastroenterol Hepatol (N Y) 2010;6:772-777.

4. Santos J, Guilarte M, Alonso C, Malagelada JR. Pathogenesis of irritable bowel syndrome: the mast cell connection. Scand J Gastroenterol 2005;40:129-140.

5. O'Sullivan M, Clayton N, Breslin NP, et al. Increased mast cells in the irritable bowel syndrome. Neurogastroenterol Motil 2000;12:449-457.

6. Wood JD. Enteric neuroimmunophysiology and pathophysiology. Gastroenterology 2004;127:635-657.
7. Ford AC, Talley NJ. Mucosal inflammation as a potential etiological factor in irritable bowel syndrome: a systematic review. J Gastroenterol 2011;46:421-431.

8. Ogilvie-McDaniel C, Blaiss M, Osborn FD, Carpenter J. Mastocytic enterocolitis: a newly described mast cell entity. Ann Allergy Asthma Immunol 2008;101:645-646.

9. Thonhofer R, Siegel C, Trummer M, Langner C. Mastocytic enterocolitis as a rare cause of chronic diarrhea in a patient with rheumatoid arthritis. Wien Klin Wochenschr 2011;123:297-298.

10. Swerdlow SH, Campo E, Harris NL, et al. WHO classification of tumours of haematopoietic and lymphoid tissues. Lyon, France: IARC, 2008.

11. Doyle LA, Sepehr GJ, Hamilton MJ, Akin C, Castells MC, Hornick JL. A clinicopathologic study of 24 cases of systemic mastocytosis involving the gastrointestinal tract and assessment of mucosal mast cell density in irritable bowel syndrome and asymptomatic patients. Am J Surg Pathol 2014;38:832-843. 